\title{
(RE)PENSANDO A RESPEITO DAS \\ NARRATIVAS DE VIAGEM "TRADICIONAIS" - DIÁSPORA COMO FORMAÇÃO DO SUJEITO TRANSCULTURAL EM UM DEFEITO DE COR
}

\author{
Camila de Matos Silva ${ }^{1}$
}

\begin{abstract}
Resumo: Este artigo propõe pensar a respeito de como tem sido conceituado e analisado as Literaturas de Viagens, bem como este gênero literário tem sido composto (quase que) exclusivamente por cânones e/ou pessoas que têm a viagem, praticamente, dentro de uma ótica positiva. Neste sentido, questionamos o lugar do negro na diáspora, da dor e da visão daqueles que inúmeras vezes não puderam (e não podem) escolher suas viagens. Para isso, elegemos o romance Um defeito de cor, de Ana Maria Gonçalves, uma vez que a narradora-personagem, Kehinde, é um sujeito transeunte - que tem a viagem como força de resistência e (auto)conhecimento. Kehinde viaja muito durante todo o romance, seja em busca do filho perdido, seja fugindo de perseguições, seja para se iniciar como vodunsí, seja para seu retorno à África e/ou ao Brasil. Seus trânsitos são cheios de muita luta e dor - mas trazem também características inegáveis da Literatura de Viagem ("tradicional), então, por que não ler a obra por esse viés? Por que ainda é tão difícil inserir nossas narrativas negras, banhadas em ejè, sangue, dentro de certas epistemologias?
\end{abstract}

Palavras-Chave: Literatura de viagem. Revisão. Mulher negra.

\section{(RE) PENSAR LAS NARRATIVAS DE VIAJES "TRADICIONALES": LA DIÁSPORA COMO FORMACIÓN DEL SUJETO TRANSCULTURAL EN LA NOVELA UM DEFEITO DE COR}

\begin{abstract}
Resumen: Este artículo propone reflexionar sobre cómo se ha conceptualizado y analizado la Literatura de Viaje, así como este género literario ha sido compuesto (casi) exclusivamente por canónigos y / o personas que tienen el viaje, prácticamente, desde una perspectiva óptica. positivo. En este sentido, cuestionamos el lugar del negro en la diáspora, el dolor y la visión de quienes innumerables veces no pudieron (y no pueden) elegir sus viajes. Para ello, elegimos la novela Um defeito de cor, de Ana Maria Gonçalves, ya que el narrador-personaje, Kehinde, es un sujeto transeúnte, que tiene el viaje como fuerza de resistencia y conocimiento de sí mismo. Kehinde viaja mucho
\end{abstract}

\footnotetext{
1 Camila de Matos Silva. Doutoranda em Teoria da Literatura UFPE/PPGL/CAPES. E-mail: camiladematossilva@gmail.com.
} 
durante todo el romance, ya sea en busca de su hijo perdido, o huyendo de la persecución, ya sea para comenzar como vodunsí, o para regresar a África y/o Brasil. Sus tránsitos están llenos de mucha lucha y dolor, pero también traen características innegables de la Literatura de Viaje (“tradicionais"), así que, ¿por qué no leer la obra de esta manera? ¿Por qué todavía es tan difícil insertar nuestras narrativas negras, bañadas en ejè, sangre, dentro de ciertas epistemologías?

Palabras Clave: Literatura de viajes. Revisión. Mujer negra.

\author{
Da língua cortada \\ digo tudo, \\ amasso o silêncio \\ e no farfalhar do meio som \\ solto o grito do grito \\ e encontro a fala anterior, \\ aquela que emudecida, \\ conservou a voz dos sentidos \\ nos labirintos da lembrança. \\ (EVARISTO, 2008)
}

\title{
(Re)pensando sobre os que ficaram e ainda estão à margem
}

Ao (re)pensarmos sobre o gênero Literatura de Viagens, algumas perguntas afloraram: como as narrativas da diáspora negra são compreendidas dentro deste gênero, aparentemente tão "elitista"? Como os traumas, as relações interpessoais e o lugar dos sujeitos negros diásporicos é entendido? Será, então, a Literatura de Viagem um gênero que deixa à margem os múltiplos processos de violência, dos quais esses sujeitos fizeram/fazem parte, sendo esses arrancados/obrigados a saírem de suas terras? Como o olhar e os sentimentos subjetivos desse tipo de transeunte é visto nas narrativas? Em que se difere de um viajante que tem nas mãos a escolha? Como as experiências de dores, violências, guerras, catástrofes também podem ser narrativas de viagem?

O que, para nós, vai definir é o intrínseco da narrativa. Neste sentido, acreditamos que as narrativas de viagens as quais abordam outros modos de viagens (que não as semanticamente positivavas), que narram sobre o latejo da dor, da saudade e a abrupta ruptura com o lugar, também podem ser lidas dentro da ótica de Literatura de Viagem. Será que mesmo em meio ao caos, à dor, à solidão ou a violências os/as narradores/as conseguem 
descrever sobre assuntos que, comumente, fazem parte de uma viagem tradicional? Ou ainda, quais os acréscimos esses narradores suscitam no texto?

Ou seja, pode parecer óbvio, simplista e redutivo: mas para nós antes de tudo uma Literatura de Viagem deve ser escrita por um viajante, e por suas experiências de viagens. O que se sucede é: essa Literatura tem se constituído de alguns tipos de viajantes em detrimentos a outros?

Percorrendo, ligeiramente, a composição da Literatura de Viagem percebemos que sua essência está ancorada em uma gênese do eurocentrismo, e de certa maneira a uma "elite" de viajantes. Esses foram os narradores eleitos durante a formação e permanência deste gênero. Nosso interesse não é tornar simplista a discussão do cânone literário dentro das narrativas de viagens, mesmo porque estamos bem cientes das múltiplas tentativas de apagamento de nossos ancestrais africanos, e de nós mulheres negras dentro das interartes e da sociedade como um todo. "Superado" isso, gostaríamos de alargar esse espaço/debate para refletirmos como a crítica literária se constituí a partir de narrativas elitistas, eurocentradas e patriarcais, bem como nossas histórias e História ancoraram todo um período escravista e pós escravista, mas, mesmo assim, nunca quiseram nos ouvir.

A intenção deste artigo é levantar questionamentos respeito das Literaturas de Viagens "tradicionais" e tentar buscar em Um defeito de cor, de Ana Maria Gonçalves, pressupostos, estéticos, que nos façam (re)pensar sobre os sujeitos viajantes da diáspora africana. Tal como a viagem é um dos grandes pontos fortes para a formação do sujeito afro-brasileiro e/ou africano desterritorializado, pelo sistema escravista. Percorrer labirintos que foram forjados e silenciados pela cultura eurocêntrica, falocêntrica, excludente e racista não tem sido tarefa fácil, pois as diversas formas de apagamento do negro advindo da diáspora africana e da cultura afro-brasileira persistiram (persistem) durante séculos de exploração colonial e pós colonial, no desejo de se contar uma História única. Chimamanda Adiche nos esclarece que "As histórias importam. Muitas histórias importam. As histórias foram usadas para espoliar e caluniar, mas também podem ser usadas para empoderar e humanizar. Elas podem despedaçar a dignidade de um povo, mas também podem reparar essa dignidade despedaçada (2019, p. 32). 
A literatura afro-brasileira, na contemporaneidade, tem cumprido importante papel de resistência e descurtinamento de novas Histórias, trazendo ao centro do discurso os que foram/são inúmeras vezes apagados da História, com destaque para a escrita de autoria feminina negra. De acordo com Evaristo (2005, p. 6), "sendo mulheres negras inviabilizadas, não só pelas páginas da História “oficial” brasileira, mas também pela literatura”. Recordamos Linda Hutcheon que ao levantar arcabouços sobre os estudos pós-modernos nos esclarece acerca das mulheres:

As mulheres devem criar e defender sua própria comunidade com base em seus próprios valores. Contudo, as mulheres negras em especial trouxeram para a recordação ex-cêntrica geral da cultura não apenas uma noção muito precisa do contexto social e da comunidade na qual trabalham, mas trouxeram também [...] uma percepção de seu próprio passado particular e histórico (HUTCHEON, 1991, p. 91).

Nossa atenção debruça-se sobre o romance Um defeito de cor, a qual se justifica pela relevância de conseguir falar sobre diversos temas, os quais ficaram à margem da História "oficial" e da formação identitária do sujeito da diáspora africana e afro-brasileira. Trazendo danos incalculáveis ao entendimento mais lúcido acerca das questões históricas, das artes, da cultura e da literatura, bem como da construção da(s) identidade(s) brasileira. Um defeito de cor, de Ana Maria Gonçalves, é tido como o primeiro romance metaficcional historiográfico, escrito por uma mulher negra brasileira, a obra possui quase mil páginas e conta outras versões da História do Brasil tida como "oficial".

Como em uma correnteza, ora águas calmas, ora turbulentas, mas que nunca cessam o bambalango, Ana Maria Gonçalves nos transporta para um século XIX pouco conhecido, ou melhor, um século XIX dito pela fala dos outros (geralmente homens brancos) e não pela voz e grafia da mulher afrobrasileira. A personagem principal, Kehinde, inicia a sua trajetória diaspórica em direção outro continente (África - América do Sul) pelas/nas correntezas do Atlântico, e ao longo de uma narrativa de buscas, encontros e desencontros vai tentando refazer e rememorar sua vida e a dos seus. É pelo olhar 
transeunte de Kehinde que a autora nos guia por vários estados do Brasil: Bahia, Minas Gerais, São Paulo, Rio de Janeiro e Maranhão - como nos conduz por outros locais na África (Uidá, Salavu, interiores). Ao ir traçando sua saga Kehinde vai revelando ao leitor fatos e personagens que ficaram à margem da História "oficial" brasileira, criando uma antinarrativa, na contramão dos discursos da Literatura de Viagem, canônica e hegemônica. Segundo Djamila Ribeiro: "Sim, esses discursos trazidos por essas autoras são contra hegemônicos no sentido que visam desestabilizar a norma, mas igualmente são discursos potentes e bem construídos a partir de outros referenciais e geografias [...]" (RIBEIRO, 2017, p. 478).

Acreditamos que o contradiscurso literário, praticado pela autora como antinarrativa, pretende tanto (re)construir a identidade afro-brasileira, bem como questionar o cânone ocidental. Notamos na fala de Schmit ao afirmar que o cânone, em terras brasileiras, valoriza determinados padrões em detrimento de outros, neste aspecto a literatura produzida por negros fica à margem:

Destoa do perfil eurocêntrico, e, portanto acaba sendo posta à margem. O cânone, isto é, um conjunto de textos que passou pelo teste do tempo e que foi institucionalizado pela educação e pela crítica como clássicos, dentro de uma tradição, vem a ser o polo irradiador dos paradigmas do quê e do como se escreve, do quê e do como se lê. Tradicionalmente, a sua constituição está pautada no processo de reprodução do mesmo, pois a força homogeneizadora que atua sobre a seleção reafirma as identidades e afinidades e exclui, portanto, as diferenças, uma vez que essas são incompatíveis com um todo que se quer uniforme e coerente em termos de padrões estéticos de excelência, argumento geralmente invocado na ratificação do estatuto canônico de uma obra (SCHMIT, 1996, p. 116).

O romance Um defeito de cor busca preencher as lacunas deixadas pelo colonizador (e pela barbárie do sistema escravista) com uma escrita/visão que descoberta/descortina as amarras do passado. Nesse sentido, Gonçalves proporciona a emergência de se falar sobre culturas até então "esquecidas" e silenciadas, a memória coletiva e individual vai 
costurando um mapa historiográfico através das múltiplas vivências e viagens de Kehinde. Pierre Nora (1993 p. 24) afirma que "Na mistura, é a memória que dita e a história que escreve." Mesmo frente às lembranças, ausências de seus familiares, rupturas, à violência e aos múltiplos deslocamentos físicos e psicológicos, realizados por Kehinde, devido à diáspora africana, percebermos que as mulheres negras ao longo da História conseguiram nutrir sentimentos como coragem e resiliência, como Luísa Mahin na Revolta dos Malês, abordada no romance. De acordo Roland Walter,

A diáspora afrodescendente das Américas deve ser entendida, portanto, como espaço diaspórico constituído por diversos lugares e comunidades heterogêneos: uma encruzilhada mediada por uma transcultura heterotópica onde existem lares e desabrigos entre lugares e mares. Viver nessa encruzilhada fronteiriça/diaspórica/transnacional/transcultural, portanto, envolve negociações através de um território fissurado [...] (WALTER, 2008, p. 42).

A experiência da diáspora, como afirmou Bhabha (1998), ocorreu dentro de embate cultural, o que justifica para nós a afirmação de Walter acerca desse sujeito transcultural que arrancado de seus países de origem são inseridos em culturas totalmente diferentes. Afirmar que apenas houveram perdas culturais é redutivo, uma vez que o contato/interação com o outro produz inevitavelmente trocas culturais.

\section{Nas correntezas rubro-negras: Kehinde uma personagem viajante}

À medida que a narrativa em Um defeito de Cor vai se desenvolvendo, os caminhos de Kehinde ganham um rumo inesperado. Prontamente aos guerreiros de Adandozan notarem que em um tapete, bordado por sua avó, havia alguns símbolos de Dan. Aos oito anos de idade em Salavu, África, no antigo Daomé, a personagem presencia o estupro e a morte de sua mãe, Dúróorîike, assim como a morte de seu irmão, Kokumo, ocorridas de maneiras brutais pelos guerreiros. Após a perda de seus entes queridos, os corpos foram enterrados em um pequeno ritual, feito por sua avó. A avó de 
Kehinde, silenciosamente, junta o que lhe é necessário e possível de se levar e faz uma "trouxa", a partir de seu gesto, as netas entendem que devem fazer o mesmo. As três iniciam um trajeto para Uidá, também em África, na esperança de recomeçarem. Este fato é descrito no primeiro subcapítulo intitulado "A viagem."

Depois de andarmos até onde nossas forças aguentaram, paramos para comer, e a minha avó disse que estávamos indo para Uidá e também não me preocupei em perguntar, pois estava mais interessada na estrada que nos levaria até lá, cheia de gente usando panos, cortes de cabelo, marcas de tribo e pinturas que eu nunca tinha visto antes (GONÇALVES, 2006, p. 26).

Compreendemos que a diáspora africana é complexa, e nossa intenção não é generalizar a relação dos trânsitos dos sujeitos dentro dos múltiplos processos, todavia nosso interesse é tentar entender como as viagens, forçadas, podem interferir para além de uma experiência de viagem, de um viajante "tradicional". O que nos chama atenção em Um defeito de cor é justamente isso, as viagens realizadas por Kehinde e todos os processos de desterritorialização parecem compor sua formação identitária. Um ponto intrigante da narrativa é que por mais que a narradora, ao longo de sua saga, viva os mais diversos traumas ela apresenta um olhar sempre resiliente perante as novas adversidades ou mudanças - que geralmente englobam deslocamentos. Desde o primeiro capítulo, percebemos o deslumbramento da narradora pelo novo:

Na maior parte do tempo seguíamos o rio, mas às vezes desviávamos das montanhas sagradas, como as formiguinhas tinham feito primeiro com o riozinho do Kokumo e depois com o riozinho da minha mãe. Mas o rio de verdade tinha outra cor, cor de barro, e em alguns lugares era verde, muito verde, cheio de plantas. Às vezes era largo como se tivesse vários outros rios dentro dele, separadas por pequenas ilhas de terra ou de mato (GONÇALVES, 2006. p. 27).

Apesar de neste excerto verificarmos a presença de traços das narrativas de viagens "tradicionais", como a descrição de elementos da 
natureza, Kehinde faz a comparação não com outras paisagens, mas com as imagens de violência do estupro e morte de sua mãe e a morte de seu irmão. A paisagem do trajeto é como um dispositivo da memória traumática da narradora, a fluidez das águas dos rios lança sua memória para o riozinho de sangue que se forma do sangue de sua mãe e de seu irmão até chegar ao iroco, quando são assassinados. Seguidamente à morte de seus entes, Kehinde, sua avó e sua irmã (gêmea) iniciam uma caminhada de Salavu a Uidá. Quando chegam a Uidá é notório o deslumbramento da personagem: “Uidá era muito mais interessante que Salavu, e a minha avó segurava as nossas mãos para que não nos perdêssemos. Eu tinha vontade de parar e ficar olhando tudo o que acontecia ao meu redor [...] (GONÇALVES, 2006, p. 29)". No mercado elas conhecem Titilayo - que sensibiliza com a situação e as levam para se hospedarem em sua casa, até conseguirem se estabelecer na cidade "A minha avó aceitou, pois também seria uma ótima oportunidade para descansarmos da viagem (GONÇALVES, 2006, p. 29)". Novamente é possível identificarmos o olhar lúdico para o desconhecido na nova cidade:

Demoramos bastante para chegar até o mar, a pé ou de boléia com um canoeiro conhecido do Akin, através de uma confusa mas bonita mistura de canais, lagoas, pequenas ilhas e bancos de areia. Eu achei que o mar era da cor do pano de Iemanjá que minha avó tinha em Salavu, só que mais brilhante e mais macio. Tocado pelo vento, o mar ia de um lado para outro, fingia que ia e voltava. A Taiwo sorriu, eu sorri e fiquei com vontade de que minha avó estivesse junto para sorrir também, se ainda soubesse (GONÇALVES, 2006, p. 30).

Apesar de suas perdas, em Salavu, e a saída de sua terra natal, Kehinde não deixa que a tristeza tome total lugar nesta nova etapa, assim ela relata: “Tenho boas recordações daquele tempo, quando tudo era novo, todos os momentos eram felizes e eu nem sequer imaginava o que ainda estava para acontecer (GONÇALVES, 2006, p. 34)". Com poucos dias em Uidá as gêmeas são capturadas "O guarda nos empurrou para dentro e ficou parado com a lança em posição [...]. Antes de sair, disse a elas para cuidarem muito bem de nós duas porque éramos ibêjis, para presentes (GONÇALVES, 2006, p. 38)". Na falta das netas a avó sai à procura das duas e quando as encontram, implora 
para ser deportada também para "o estrangeiro" - como assim chamavam. Outra passagem nos atenta para a forma como ocorre essa viagem forçada: “Todos os dias chegava mais gente capturada em muitos lugares da África, falando línguas diferentes e dando várias versões sobre nosso destino (GONÇALVES, 2006, p. 38)".

Uma nova viagem se inicia para narradora, em outro subcapítulo também intitulado "A viagem", sem que ainda tivesse tempo para digerir tantas perdas e sem chances de recomeçar. As águas marcam a vida de Kehinde, que embarca para o Brasil com sua avó e sua irmã-"O tumbeiro apitou e partiu pouco depois que paramos de ouvir os barulhos na parte de cima, quando acabaram de acomodar todos os homens (GONÇALVES, 2006, p. 46). Recordamos que as águas rubro-negras (GILROY, 2001) são grandes marcas para as viagens dos sujeitos desterriorizados, águas onde o ejè, sangue, foi por séculos derramado e acompanhou a travessia da maioria dos escravizados.

Quando alguém disse que já não cabia mais ninguém, recebeu a resposta de que o balanço do navio deveria caber. [...]. Deitada no escuro, olhando o céu sem estrelas do teto do porão, se não fosse o cheiro que fazia o ar entrar difícil no peito, eu teria gostado de ser embalada pelo mar. Ele fez com que eu me lembrasse de quando a minha mãe nos embalava, a mim e à Taiwo de uma só vez, indo e voltando no ritmo de uma música que ela inventava na hora. A minha mãe tinha voz bonita, que foi embora navegando no riozinho de sangue que se juntou ao riozinho do Kokumo. Esse foi o cheiro que, apesar de disperso no meio dos outros, me acompanhou durante toda a viagem desde o armazém: o cheiro de sangue (GONÇALVES, 2006, p. 46).

Paul Gilroy salienta que a experiência da diáspora está inteiramente ligada à formação da identidade negra, como um construto social, político e histórico, relacionada a partir de suas trocas e vivências com o cenário do Atlântico. No caso de Kehinde, a sua primeira experiência com o Atlântico [como viajante] é traumática e animalizada. 
Em oposição às abordagens nacionalistas ou etnicamente absolutas [da cultura], quero desenvolver a sugestão de que os historiadores culturais poderiam assumir o Atlântico como uma unidade de análise única e complexa em suas discussões do mundo moderno e utilizá-la para produzir uma perspectiva explicitamente transnacional e intercultural (GILROY, 2002, p. 57).

A viagem, forçada, no tumbeiro do "Navio Negreiro" muda mais uma vez o destino da narradora, dentro do navio ela relata "Vistos do alto, devíamos estar parecendo um imenso tapete, deitados no chão sem que houvesse espaço entre um corpo e outro, um imenso tapete preto de pele de carneiro (GONÇALVES, 2006, p. 47)". Retomando a questão da formação identitária, da personagem, aqui temos uma emblemática questão: a destituição dessas identidades ao serem escravizados e animalizados.

Ainda durante sua trajetória, ao Brasil, a narradora perde primeiro a sua irmã, cuja morte é significativa, pois sendo ibêjis era como se tivessem a mesma alma - neste sentido, a narrativa nos atenta para uma formação ainda mais complexa, uma vez que sem sua outra parte e sem alguns rituais para que a alma de sua irmã fique sempre ao lado da narradora isso dificulta, tornando ainda mais emblemático a formação identitária dessa personagem. Em seguida morre a sua avó, a qual ainda conseguiu ensinar para a neta algumas coisas sobre voduns e orixás, como uma espécie de herança/legado ancestral, e também o fechamento de um ciclo - fazendo toda diferença na saga e na identidade de Kehinde. Segundo Stuart Hall (2006, p. 7), a modernidade promoveu a "crise de identidade" - devido à reflexão feita a partir de um processo "mais amplo de mudança, que está deslocando estruturas". De acordo, ainda, com o pesquisador:

O sujeito, previamente vivido como tendo uma identidade unificada e estável, está se tornando fragmentado; composto não de uma única, mas de várias identidades, algumas vezes contraditórias ou não resolvidas. Correspondentemente, as identidades, que compunham as paisagens sociais -lá fora\| e que asseguravam nossa conformidade subjetiva como as -necessidades\| objetivas da cultura, estão entrando em colapso, como resultado de mudanças estruturais e institucionais. $\mathrm{O}$ 
próprio processo de identificação, através do qual nós projetamos em nossas identidades culturais, tornou-se mais provisórios, variável e problemático (HALL, 2006, p. 12).

Durante toda a viagem, trancada dentro de um porão fétido, Kehinde vai se formando enquanto sujeito múltiplo, a exemplo, seu interesse pelos hábitos dos muçulmanos: "Os muçurumins eram os que mais reclamavam, nem tanto pelas condições em que viajávamos pois segundo a Aja, qualquer sacrifício valia a pena se fosse por Alá, mas porque não estavam conseguindo cumprir as obrigações da religião (GONÇALVES, 2006, p. 49). Tal interesse pelos muçulmanos perpetua em sua saga, desencadeando uma amizade sincera com Fatumbí - o que a leva a participar da Revolta dos Malês anos mais tarde. Como única sobrevivente de sua família, a protagonista resiste e desembarca no Brasil, na Ilha de Itaparica/BA:

Eu me senti quase feliz ao avistar a Ilha dos Frades. Uma felicidade que talvez pudesse ter sido chamada de alívio, como aconteceria várias outras vezes em minha vida. Por causa da beleza da ilha, fiquei impressionada com as cores, com o ar, com as novas sensações, com a esperança de tudo nem ser tão ruim assim. Ao subir as escadas do porão e ver primeiro o céu azul, depois a luz do sol quase me cegando, fazendo com que os outros sentidos ficassem mais atentos. Tive vontade de nascer de novo naquele lugar e ter comigo os amigos de Uidá. [...]. Nascer de novo e deixar na vida passada o riozinho de sangue do Kokumo e da minha mãe, os meus olhos nos olhos cegos da Taiwo, o sono da minha avó (GONÇALVES, 2006, p. 46).

Mesmo desterritorializada e sozinha, Kehinde possui olhares de uma viajante "quase" comum, ela narra a beleza do lugar e afirma querer "nascer de novo", deixando para traz suas lembranças doloridas, no entanto sua saga como escravizada estava apenas se iniciando... Logo depois de passar uma boa parte de sua infância na Ilha de Itaparica/BA, escravizada, o sinhô morre e a vida de Kehinde segue novamente outro rumo. A sinhá, Ana Felipe, decidi mudar-se para Salvador levando Kehinde, grávida de um estupro do sinhô, juntamente com outros escravizados da casa-grande. 
Kehinde é a personagem que migra, que viaja e assim como as correntezas que ora estão calmas, ora estão revoltosas, ela consegue percorrer um caminho árduo, mas de muita resistência e coragem. "Eu tinha a sensação se ser sempre uma viajante, por causa de tantos lugares que conheci sem adotar nenhum em definitivo, enquanto a maioria dos pretos quase nunca se afastava da casa dos sonos, principalmente os que iam para as fazendas" (GONÇALVES, 2006, p. 710). E foi procurando nos concentrarmos à forçamotriz que o romance carrega e à resiliência, da personagem, que pudemos ler em cada história, em cada personagem o anseio por um discurso contra hegemônico, de denúncia e necessidade de novas vertentes dentro da Literatura Brasileira canônica. Roland Walter em suas considerações sobre a escrita negra de autoria feminina, afirma que:

Em grande parte da escrita negra de autoria feminina, "as políticas de localização" espaciais são ao mesmo tempo sexuais: primeiro, a "espacialização" da escravidão e do colonialismo que colocaram a mulher negra no navio negreiro, nas senzalas e casas grandes das plantações e cidades; segundo, as diversas fases de "quilombização" da resistência com objetivo de reapropiar e recriar esse espaço confinado, colocando a mulher negra na rota da migração (WALTER, 2009, p. 216).

A narradora passa boa parte da obra nesta "rota de migração". Em uma das rotas Kehinde vai para o Maranhão e auxilia na fundação das Casas das Minas, onde ocorre o culto jeje Mahin - um dos mais antigos do país, porém não permanece muito tempo, tornando-se viajante novamente:

Aprendi muitas coisas, mas ainda havia muitas outras para aprender, e quando conversei com a noche Naê sobre isso, ela comentou que o meu aprendizado não se complementaria na Casa das Minas, que havia um outro local onde eu me desenvolveria melhor, e falou de uma Casa em Cachoeira, no Recôncavo. [...]. A viagem durou quase sete dias em um saveiro que transportava carga, que não me interessei em saber qual era [...] (GONÇALVES, 2006, p. 603). 
Essa viagem é uma das mais significativas para formação identitária da personagem, visto que ela passará três anos reclusa para sua formação como vodunsí, "O meu ritual de iniciação foi um dos momentos mais felizes que já vivi, quando finalmente pude receber meu vodum, que me disse coisas lindas por intermédio de uma das hunjáís da Roça (GONÇALVES, 2006, p. 629)". Leda Martins afirma que:

Com nossos ancestrais vieram as suas divindades, seus modos singulares e diversos de visão de mundo, sua alteridade lingüística, artísticas, étnicas, religiosas, cultural, suas diferentes formas de organização social e de simbolização do real. As culturas negras que matizaram os territórios americanos, em sua formulação e modos constitutivos, evidenciam o cruzamento das tradições e memórias orais africanas com todos os outros códigos e sistemas simbólicos, escritos e / ou ágrafos, com que se confrontaram. E é pela via dessas encruzilhadas que também se tece a identidade afro-brasileira (MARTINS, 1997, p. 26).

Novamente a vida da personagem é marcada pelo trauma, uma vez que enquanto estava reclusa para sua iniciação seu segundo filho é vendido, pelo próprio pai - um português - como escravizado. A narradora inicia uma longa saga, rica em acontecimentos e experiências. Ela percorre Bahia, Rio de Janeiro, São Paulo, Campinas, Santos: “Dois dias depois eu estava novamente a caminho de Santos, descendo aquela serra com a mesma dificuldade com que tinha subido e pensando em e pegar o primeiro navio para São Salvador (GONÇALVES, 2006, p. 723)". Cansada e sem notícias do paradeiro do filho ela decidi voltar para Uidá, em África, agora alforriada e dona da escolha de voltar à sua terra natal.

A viagem durou vinte e seis dias. Saí de São Salvador a vinte e sete de outubro de um mil e oitocentos e quarenta e sete e desembarquei em Uidá a vinte e dois de novembro, no mesmo local onde tinha partido trinta anos antes. As situações eram distintas, mas o medo era quase igual, medo do que ia acontecer comigo dali em diante. É claro que os motivos também eram diferentes, porque naquela volta eu seria a única responsável pelo meu 
destino, e na partida tudo dependia daqueles que tinham me capturado (GONÇALVES, 2006, p. 731).

Kehinde ao iniciar a carta/capítulo nove [capítulo que marca sua volta] cita o seguinte provérbio africano: "Mesmo o leito de um rio ainda guarda o seu nome". Nesse sentido, entendemos que o retorno é ambíguo, uma vez que o retorno à África vai florescer na personagem muitos sentimentos ligados à sua ancestralidade, por ser um sujeito que vivenciou a diáspora forçada e, nesse sentido, vive o entre-lugar ocasionado pelos embates culturais, como Homi Bhabha nos elucida sobre esta "negociação complexa":

O "direito" de se expressar a partir da periferia do poder e do privilégio autorizados não depende da persistência da tradição; ele é alimentado pelo poder da tradição de se reinscrever através de contingência e contraditoriedade que presidem sobre a vida dos que estão na "minoria". O reconhecimento que a tradição outorga é uma forma parcial de identificação. Ao reencenar o passado, este introduz temporalidades culturais incomensuráveis na invenção da tradição. Esse processo afasta qualquer acesso imediato a uma identidade original ou a uma tradição "recebida". Os embates da fronteira acerca da diferença cultural têm tanta possibilidade de serem consensuais quanto conflituosos; podem confundir nossas definições de tradição e modernidade, realinhar as fronteiras habituais entre o público e o privado, o alto e o baixo, assim como desafiar as expectativas normativas de desenvolvimento e progresso (BHABHA, 1998, p. 19).

Ao "reencenar o passado" Kehinde nos lança em um redemoinho complexo e conflituoso. O embate cultural mencionado por Bhabha proporciona à personagem uma gama de fatores positivos, como o fato de tornar-se poliglota, entretanto quando chega ao Brasil é obrigada a parar se comunicar em sua língua de origem. Ainda sobre o embate cultural, Homi Bhabha assinala:

Os termos do embate cultural, seja através de antagonismos ou afiliação, são produzidos performaticamente. A representação da diferenciação não deve ser lida apressadamente como reflexo de traços culturais ou étnicos preestabelecidos, [...]. A articulação 
social da diferença, da perspectiva da minoria, é uma negociação complexa, em andamento, que procura conferir autoridade aos hibridismos culturais que emergem em momentos de transformação histórica (BHABHA, 1998, p. 20-21,).

Nessa sequência, a personagem principal vai descrever a situação dos ex-escravizados africanos, “desterritorializados", muitos são os que deixaram o Brasil e retornaram para África na esperança de encontrar o "paraíso", mas se decepcionaram ao regressarem, como conta ao chegar a Uidá:

Eu não me lembrava muito bem da África que tinha deixado, portanto, não tinha muitas expectativas em relação ao que encontraria. Ou talvez, na época, tenha pensado isso apenas para me conformar, porque não gostei nado do que vi. Nem eu nem os companheiros de viagem que estavam retornando, como o Acelino e o Fortunato, que se lembravam de um paraíso, imagem bem distante da que tínhamos diante de nós (GONÇALVES, 2006, p. 731).

O regresso desses africanos, incluindo a narradora, traz não somente os valores culturais africanos, mas também alguns valores adquiridos na experiência da diáspora em solos brasileiros. A protagonista admite que ao retornar, do Brasil, sua percepção sobre aquele lugar e aquelas pessoas foi alterada, e que ela também considera os africanos selvagens. Tal olhar parte de sua experiência:

Os brasileiros faziam questão de conversar somente em português, e acho que isso acabava contribuindo para a fama de arrogantes, que aumentava a cada dia. Alguns já tinham construído casas que se pareciam o mais possível com as casas da Bahia, fazendo com que se destacasse muito das casas pobres, feias e velhas dos africanos. Eu também queria uma daquelas, que eram o sonho de todo retornado e até alguns africanos, embora eles não admitissem, por causa das rivalidades. Todos os retornados se achavam melhores e mais inteligentes que os africanos. Quando os africanos chamavam os brasileiros de escravos traidores, dizendo que tinham se 
vendido para os brancos e se tornando um deles, os brasileiros chamavam os africanos de selvagens, de brutos, de atrasados e pagãos. Eu também pensava assim, estava do lado dos brasileiros, [...] (GONÇALVES, 2006, p. 756).

Na estreita ligação África-Brasil, História-Memória é que Kehinde aborda os "brasileiros", retornados do Brasil, os quais se instauram no Golfo do Benin. Essa região africana representa um exemplo único de implantação de uma cultura brasileira - no caso, baiana, visto que os "retornados" são constituem apenas uma colônia de brasileiros, todavia um grupo social que se reconhece como brasileiro, e se utiliza dessa condição para se articular com o conjunto da sociedade. Tal grupo é conhecido como os agudás. Kehinde é uma agudá que retorna ao seu país de origem e ao retornar mostra-se bastante ligada à cultura dos brasileiros. Roland Walter nos esclarece acerca da experiência coletiva, de troca, na diáspora e formação identitária:

Viver sem limites e fronteiras, tornar-se uma encruzilhada diaspórica, significa que a subjetividade evocada nesta existência é constituída por múltiplas trajetórias históricas, linguísticas, étnico-raciais eculturais. Significa abrir-se para os outros fora e dentro de si, ou seja, aceitar e respeitar diferenças. Se a construção social de lugares em espaços transnacionais e transculturais informa a episteme, então é crucial lembrar que noções de identidade, ethos, cosmovisão, lugar, espaço, fronteira, tempo e agir interagem e se caracterizam mutuamente. O conceito da diáspora e a teorização na/da encruzilhada diaspórica e transcultural pode fornecer uma compreensão antiessencialista de formações identitárias e de cidadanias interculturais e transnacionais (WALTER, 2008, p. 43).

Depois de anos em África, já em Lagos, cega e velha, a narradora encontra um possível rastro do filho perdido e novamente decidi atravessar o Atlântico em busca desse. Um retorno ambíguo em relação à viagem, porque não fica explicito para o leitor se Kehinde resiste à viagem, sendo a viagem entendida, aqui também, como metáfora de vida e morte. 


\section{Considerações (nada) finais}

Kehinde é um sujeito que se forma pelo coletivo, ao longo de sua experiência diaspórica tece histórias, cartografa paisagens, lugares de um Brasil em pleno século XIX, carrega em si sua ancestralidade, mas adquire no "embate cultural" modos, visões que acabam por comporem sua identidade. Negociações nem sempre conciliadoras, como por exemplo, quando volta para África e financia o tráfico de armas para os ingleses - esses que mesmo incentivando o fim do tráfico agiam diretamente na venda de armas para o tráfico de escravizados. Ou seja, os vários deslocamentos da narradora possibilitaram a ela uma formação transcultural, Kehinde fala eve, fon, inglês e português, leu vários livros durante sua vida, tornou-se uma comerciante nata, dona de padaria, fábrica de charutos, comerciante de cookies, mercadorias africanas, armas, e até mesmo chegou a montar uma construtora em África.

Kehinde é antes de tudo uma colecionadora de memórias, as quais na maioria foram de suas viagens. Por esse viés, acreditamos que a narrativa de viagem é antes de tudo um texto mnemônico, que se territorializa na escrita. Kenhide é esse sujeito desterritorializado, transcultural que vive no limiar do entre-lugar, que enfrenta inúmeros desafios, passa por grandes processos traumáticos, porém mesmo perante a tantas atrocidades: ela resiste e encontra coragem sempre para recomeçar e/ou viajar.

\section{Referências}

ADICHE, Chimamanda Ngozi. O perigo de uma história única. Trad. Julia Romeu. São Paulo: Cia das Letras, 2019.

BHAHBA, Homi k. O local da Cultura. Belo horizonte: tradução de Myriam Avila, Eliane Livia Reis, Glauce Gonçalves. Belo Horizonte. Ed. UFMG, 1998.

BERND, Zilá. Em busca dos rastros perdidos da memória ancestral: um estudo de Um defeito de cor, de Ana Maria Gonçalves. Estudos de Literatura Brasileira Contemporânea. 2012.Disponível em http://www.scielo.br/pdf/elbc/n40/a03n40.pdf. Acesso em 20 de julho de 2017. 
EVARISTO, Conceição. Poemas de Recordação e outros movimentos. Belo Horizonte: Nandyala, 2008.

GILROY, Paul. OAtlântico Negro. Modernidade e dupla consciência. Tradução Cid Knipel Moreira. UCAM: 2002.

GLISSANT, Edouard. Introdução a uma poética da diversidade. Trad. Enilce Albergaria Rocha. Juiz de Fora: UFJF, 2005.

GONÇALVES, Ana Maria. Um defeito de cor. Rio de Janeiro. Editora Record, 2006.

HALL, Stuart. A identidade em cultural na pós-modernidade. Tradução Tomaz Tadeu da Silva e Guacira Lopes Louro. DP \&A Editora, 1a edição em 1992, Rio de Janeiro, 11ª edição em 2006.

MARTINS, Leda. Afrografias da memória: O reinado do Rosário no Jatobá. Belo Horizonte: Mazza, 1997.

MARTINS, Leda Maria. A fina lâmina da palavra. Revista O eixo e a roda. V. 15, 2007.

NORA, Pierre. Entre memória e história a problemática dos lugares. Tradução Khaoury, Y.A. Revista do Programa em estudos pós graduados em história e do departamento de história: PUC São Paulo, 1993.

RIBEIRO, Djamila. O que é lugar de fala? Belo Horizonte: Justificando, 2017.

RICOEUR, Paul. A memória, a história, o esquecimento. Tradução Alain François [et al.]. - Campinas, SP: Editora da Unicamp, 2007.

WALTER, Roland. Tecendo Identidade, tecendo cultura: os fios da memória na literatura afrodescendente das Américas. XI Congresso Internacional da ABRALIC - Tessituras, Interações, Convergências. São Paulo. USP 13 -17 de julho de 2008.

WALTER, Roland. Mobilidade cultural: o (não-)lugar na encruzilhada transnacional e transcultural. Interface Brasil/Canadá, Rio Grande, n. 8, 2008. Disponível

em:

https://periodicos.ufpel.edu.br/ojs2/index.php/interfaces/article/view/6960 .Acesso em 17 de agosto de 2017.

WALTER, Roland. Afro-América: Diálogos Literários na Diáspora Negra das Américas. Coleção Letras. Bagaço, 2009.

Recebido em 2 de setembro de 2020.

Aceito em 30 de outubro de 2020. 